\title{
ANÁLISE DE DADOS DOS PROTOCOLOS DE MORTE ENCEFÁLICA E DE DOAÇÃO DE ÓRGÃOS REALIZADOS NO NORTE DE MINAS GERAIS NO PERÍODO DE JANEIRO DE 2018 A JANEIRO DE 2019
}

\author{
Analysis of data from brain death protocols and organ donation performed in the Northern \\ Minas Gerais state from January, 2018 to January, 2019 \\ Carlos Rafael Lima Monção', Silvânia Paiva dos Santos², Nayara Prats Ferreira², \\ Stephânia Campos Lobato³ ${ }^{3}$ Keury Soares Xavier ${ }^{3}$
}

\section{RESUMO}

Introdução: A morte encefálica (ME) é definida como a parada total e irreversível da atividade do tronco cerebral e hemisférios cerebrais, diagnosticada através de dois exames clínicos e um exame complementar. O diagnóstico de ME e o processo de doação de múltiplos órgãos são temas complexos, e devem ser melhor pesquisados sobretudo na realidade brasileira. Objetivos: Analisar dados dos protocolos de morte encefálica e da doação de órgãos na Instituição Santa Casa de Misericórdia de Montes Claros - Minas Gerais. Métodos: Foi realizada pesquisa quantitativa, descritiva e retrospectiva, baseada em dados coletados na Santa Casa de Montes Claros Minas Gerais. Através da revisão de prontuário, foram analisados todos os pacientes elegíveis ao protocolo de morte encefálica de janeiro de 2018 a janeiro de 2019. Os dados foram organizados em uma planilha Excel composta das seguintes variáveis: sexo, idade, causa do óbito, exame comprobatório de $\mathrm{ME}$, tempo da abertura do protocolo até a conclusão, contraindicações à doação, causa da recusa familiar e órgãos captados para doação. Resultados: Foram evidenciadas 92 suspeitas de morte encefálica, das quais somente 42 protocolos de ME foram concluídos com 18 doações de múltiplos órgãos e 13 recusas familiares. Conclusões: No presente estudo, constatou-se que a maior causa de ME foi AVE hemorrágico; $48 \%$ das suspeitas de ME tinham contraindicações à doação, além da recusa familiar de $42 \%$ dos potenciais doadores.

Descritores: Obtenção de Tecidos e Órgãos; Transplante; Morte Encefálica

Instituições:

1. Departamento de Clínica Médica do Centro Universitário FIPMoc Montes Claros/MG - Brasil

2. Departamento de Enfermagem da Santa Casa de Montes Claros Montes Claros/MG - Brasil

3. Departamento de Clínica Médica da Santa Casa de Montes Claros Montes Claros/MG - Brasil

\section{Correspondência:}

Carlos Rafael Lima Monção

Rua Tupinambás, 13, s/1312, CEP 39401-509 Montes Claros/MG - Brasil Email: crmoncao.crm@gmail.com

Tel.: (38) 98828-1692

Recebido em: 02/03/2019 Aceito em: 30/03/2019

\section{INTRODUÇÃO}

O transplante e doação de órgãos humanos têm provocado interesse e discussões em meio à sociedade. A maior dificuldade na realização do transplante é a recusa das famílias em doar os órgãos do ente querido, o que contribui para o número insuficiente de doadores e para a crescente demanda de listados no Cadastro Técnico Único (CTU). ${ }^{1}$

O processo de doação de múltiplos órgãos é complexo e requer uma cuidadosa avaliação de diversas informações e a correta execução de inúmeros procedimentos e etapas. Inicialmente, deve-se identificar os pacientes que se enquadram nos critérios de morte encefálica, ou seja, aqueles que apresentam lesão encefálica conhecida e irreversível, tais como traumatismo cranioencefálico 
Análise de dados dos protocolos de morte encefálica e de doação de órgãos realizados no Norte de Minas Gerais no período de janeiro de 2018 a janeiro de 2019

grave, acidente vascular encefálico extenso e encefalopatia hipóxico-isquêmica. Esses pacientes se encontram em coma não perceptivo, em apneia e não devem possuir fatores que possam confundir o diagnóstico de ME. Assim, os procedimentos para determinação de ME devem ser iniciados e a Organização de Procura de Órgãos (OPO) e a Comissão Hospitalar de Transplantes (CHT) devem ser obrigatoriamente informadas.

Com o auxílio da OPO e da $\mathrm{CHT}$, a equipe de profissionais de saúde responsável pelo paciente em protocolo de ME deve garantir que todos os pré-requisitos necessários estejam presentes, assegurar que os dois exames clínicos, o teste de apneia e o exame complementar comprovando ausência de atividade ou fluxo sanguíneo encefálico sejam corretamente realizados e registrados no prontuário hospitalar, além do Termo de Declaração de Morte Encefálica. Após a conclusão da determinação da ME, o médico assistente do paciente ou seu substituto (plantonista) realizará a comunicação de morte aos familiares. Os profissionais da OPO avaliam as contraindicações absolutas ou relativas à doação de órgãos, as condições clínicas do potencial doador e realizam a entrevista familiar. Caso a família ou responsável legal seja favorável à doação e o termo de autorização de doação de órgãos e tecidos esteja corretamente preenchido e assinado, a OPO realizará a notificação ao Sistema Nacional de Transplantes (SNT), que irá distribuir os órgãos e tecidos para posterior captação pelas equipes transplantadoras. . $^{2,3}$

Os profissionais que atuam na Comissão Hospitalar de Transplantes (CHT) precisam trabalhar em conjunto com aqueles que prestam atendimento direto ao paciente, pois estes devem ser informados, caso haja suspeita de possível doador nos setores onde trabalham. Considerase potencial doador, o paciente com diagnóstico clínico de ME sem contraindicação para a doação. ${ }^{4}$

A dificuldade no entendimento a respeito do diagnóstico de $\mathrm{ME}$, as notícias sensacionalistas sobre tráfico de órgãos, a falta de programas de educação continuada voltados para a conscientização da sociedade e a ausência de estímulo para a captação de órgãos, contribuem para a ocorrência de incertezas, mitos e preconceitos relacionados ao tema. Além disso, a abordagem dos familiares sobre a doação de órgãos dá-se no momento em que a família vivencia o luto, período de extrema dor e sofrimento com a notícia da morte. Essa abordagem torna-se ainda mais difícil diante de um potencial doador jovem e vítima de morte trágica. ${ }^{1}$

O Brasil é o segundo país do mundo em números absolutos de transplantes, com a política instituída pelas Leis $n^{\circ} 9.434 / 1997$ e 10.211/2001, que têm como diretriz a "gratuidade da doação, a beneficência em relação aos receptores, a não maleficência em relação aos doadores vivos. ${ }^{4,5}$

Os registros da Associação Brasileira de Transplantes de Órgãos (ABTO) mostram acréscimo de apenas 2,4\% na taxa de doadores efetivos, passando de 16,6 pmp em 2017, para 17,0 pmp em $2018 ; 5,5 \%$ abaixo da taxa prevista $(18,0 \mathrm{pmp})$. A taxa de recusa familiar mantevese em $43 \% .^{5}$

Conforme a Portaria $1.752 / 2005$, todos os hospitais brasileiros, públicos, privados e filantrópicos que possuam mais de 80 leitos devem instituir a Comissão Intrahospitalar de Doação de Órgãos e Tecidos para Transplantes (CIHDOTT). Dentre as funções estabelecidas, destacam-se a detecção e notificação à Central de Notificação, Captação e Distribuição de órgãos (CNCDO) dos potenciais doadores de órgãos e tecidos na instituição, bem como a viabilização do diagnóstico de ME, de acordo com o Conselho Federal de Medicina (CFM) e a criação de rotinas para proporcionar aos familiares do paciente a possibilidade de doação. ${ }^{6}$

A Santa Casa de Montes Claros, local onde foi realizado o presente estudo, atende a população do norte de Minas Gerais (MG) e sudoeste da Bahia. Atualmente possui 392 leitos. Destes, 30 leitos são de Unidade de Terapia Intensiva (UTI) Geral, Coronariana e Neonatal. Aproximadamente, $80 \%$ dos leitos são destinados ao Sistema Único de Saúde (SUS). Em 2017, foram realizados mais de um milhão e meio de atendimentos. $A$ CIHDOTT da Santa Casa de Montes Claros foi implantada em 2006, conforme a exigência legal. É constituída por equipe multiprofissional, e conta com a atuação de uma coordenadora médica e uma enfermeira exclusiva para desempenhar a função de desenvolver o processo de captação de órgãos e tecidos, juntamente com o apoio dos demais membros da comissão e da Organização de Procura de Órgãos (OPO).

Diante do exposto, o estudo objetivou analisar os dados dos protocolos de morte encefálica e da doação de órgãos na Instituição Santa Casa de Misericórdia de Montes Claros - Minas Gerais.

\section{MÉTODOS}

Trata-se de pesquisa exploratória descritiva com abordagem quantitativa. ${ }^{7} \mathrm{O}$ campo de ação deste estudo foi a Irmandade Nossa Senhora das Mercês de Montes Claros (Santa Casa de Montes Claros).

A OPO Norte- Nordeste de Minas Gerais sediada em Montes Claros dispõe de registro específico denominado "Dados adicionais de pacientes em suspeita de morte encefálica", adotado pela CIHDOTT da Santa Casa de 
Montes Claros. Nesse documento, há informações sobre o possível doador, tais como: número do atendimento, setor de internação, dados pessoais, data da notificação, causa mortis, horário da última sedação, drogas utilizadas, familiar responsável, grau de parentesco, abordagem realizada ou não, responsável pela entrevista e motivo da recusa. O preenchimento do formulário é de responsabilidade da enfermeira da CIHDOTT ou da equipe da OPO.

Após ser avisado sobre a existência do potencial doador, o profissional da CIHDOTT ou OPO dirige-se até o setor onde o paciente está internado, avalia as condições clínicas, preenche o formulário mediante informações contidas no prontuário e disponibiliza o "Termo de Declaração de Morte Encefálica". Esse documento é preenchido por médicos responsáveis pela realização dos exames comprobatórios para diagnóstico de ME, conforme estabelecida pela Resolução CFM n $2.173 / 2017 .{ }^{8}$

Consideraram-se neste estudo, todos os casos com diagnóstico firmado de ME ocorridos entre janeiro/2018 e janeiro/2019. A coleta de dados ocorreu de forma retrospectiva e documental, mediante a utilização de planilha no Excel elaborada pelos pesquisadores.

O instrumento foi composto pelas seguintes variáveis: sexo, idade, causa do óbito, exame comprobatório de $\mathrm{ME}$, tempo da abertura do protocolo até a conclusão, contraindicação da doação, causa da recusa, órgãos captados para doação.

O presente estudo foi aprovado pelo Comitê de Ética e Pesquisa da Universidade Estadual de Montes Claros, conforme exigência da Resolução 466/2012, respeitando o anonimato das informações e a privacidade dos pacientes envolvidos, com o parecer favorável no dia 09 de junho de 2019 e registro de número 3.379.269. ${ }^{9}$

Foram incluídos no estudo pacientes com os prérequisitos necessários para determinação de morte encefálica (coma não perceptivo, apneia e ausência de fatores que possam confundir o diagnóstico de ME) com idade maior que sete dias de vida e com registro adequado no prontuário sobre a suspeita de morte encefálica por médico capacitado.

Foram excluídos casos com ausência de registros legíveis e claros no prontuário médico, ausência de exames de neuroimagem, os pacientes com idade menor que sete dias de vida e aqueles com causa de ME desconhecida. Além disso, casos que foram identificados por documentos oficiais e doadores somente de córnea por morte decorrente de coração parado (sem ME).

Os dados foram analisados por percentuais simples e apresentados em forma de gráficos e tabelas, permitindo a visualização. Os percentuais foram calculados de acordo com o total de 92 registros (100\%) firmados com diagnóstico de ME.

\section{RESULTADOS}

Entre janeiro/2018 e janeiro/2019, foram evidenciados 92 casos de Morte Encefálica (ME) no hospital Santa Casa de Montes Claros, sendo notificados 85 casos e aberto protocolo para Morte Encefálica para 72. Destes, 42 foram concluídos e apenas 31 famílias foram abordadas sobre a doação de órgãos; os demais (11 casos) não foram abordados por apresentarem contraindicações absolutas à doação (Figura 1).

Figura 1: Distribuição dos desfechos dos protocolos de morte encefálica. Montes Claros. 2019. $n=92$.

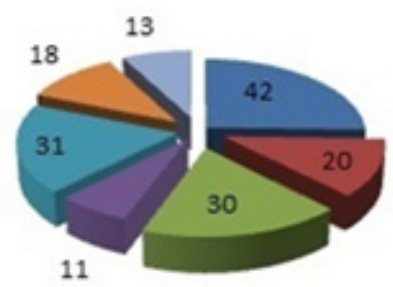

- Protocolos concluídos

a Protocolos não iniciados

- Protocolos não concluídos

- Familias nåo abordadas

- Familias abordadas

Fonte: Santa Casa de Montes Claros, 2019

Foi obtido êxito para doação em 18 abordagens familiares disponibilizando para transplante três corações, 25 rins e oito fígados. Os demais 13 casos obtiveram recusa familiar. Dentre os motivos que influenciaram a recusa familiar, identificou-se a não compreensão sobre o que realmente representa a morte encefálica e o medo de estar contribuindo para a morte do familiar.

Quanto às contraindicações à doação presentes em 41 casos, a sepse liderou como principal causa, com 17 casos (41\%). Tumores, sorologias positivas, Doença de Chagas e idade avançada também contribuíram em menores proporções (Figura 2).

Figura 2: Causas das contraindicações às doações de órgãos nos protocolos de morte encefálica. Montes Claros. 2019. $n=41$

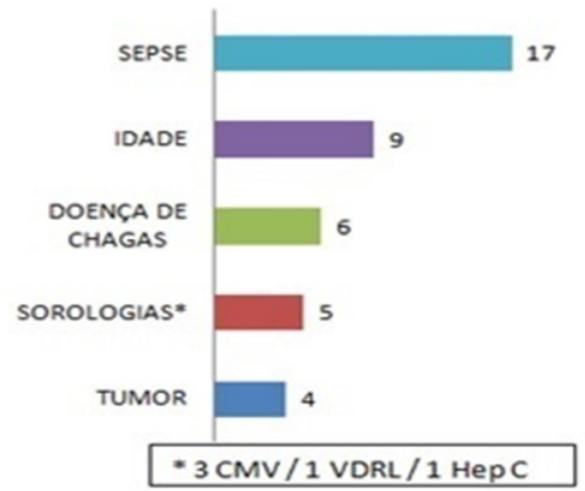

Fonte: Santa Casa de Montes Claros, 2019 
Análise de dados dos protocolos de morte encefálica e de doação de órgãos realizados no Norte de Minas Gerais no período de janeiro de 2018 a janeiro de 2019

Dentre as causas de morte, prevaleceram: Acidente Vascular Encefálico (AVE) hemorrágico com 15, Traumatismo Cranioencefálico (TCE) com 13 e AVE isquêmico com sete ocorrências (Tabela 1).

Tabela 1: Causas de Morte Encefálica na Santa Casa de Montes Claros no período de janeiro de 2018 a janeiro de 2019

\begin{tabular}{lc}
\hline \multicolumn{1}{c}{ Motivo } & Número Total 42 \\
\hline AVE hemorrágico e/ou hemorragias intracranianas & $15(36 \%)$ \\
\hline AVE isquêmico & $7(16,5 \%)$ \\
\hline Traumatismo Cranioencefálico (TCE) & $13(31 \%)$ \\
\hline Encefalopatia hipoxêmica pós-PCR & $3(7 \%)$ \\
Neoplasia gástrica com metástase cerebral & $1(2 \%)$ \\
Tumor de hipófise & $1(2 \%)$ \\
\hline Tumor intracerebral primário & $1(2 \%)$ \\
\hline Holoprosencefalia & $1(2 \%)$ \\
\hline
\end{tabular}

Fonte: Santa Casa de Montes Claros, 2019

O sexo masculino representou 53 casos de ME, sendo que 11 foram doadores. No sexo feminino, foram 32 casos, sendo sete doadoras. A faixa etária predominante como doadores foi entre 36 e 60 anos, em uma amostra que variava de zero a 70 anos. (Figura 3).

Figura 3: Distribuição por faixa etária dos doadores de múltiplos órgãos na Santa Casa de Montes Claros no período de janeiro de 2018 a janeiro de 2019.

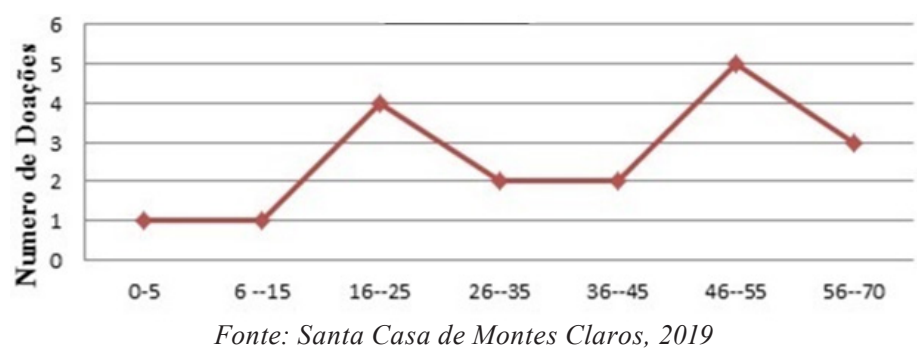

Quanto ao setor de internação que o paciente se encontrava no momento do diagnóstico de ME, a internação em UTI obteve maior índice de aceitação familiar à doação de órgãos (Figura 4).

Figura 4: Números de protocolos de morte encefálica, de doações realizadas e de contraindicações distribuídos conforme os setores de internacão. Santa Casa de Montes Claros. 2019.

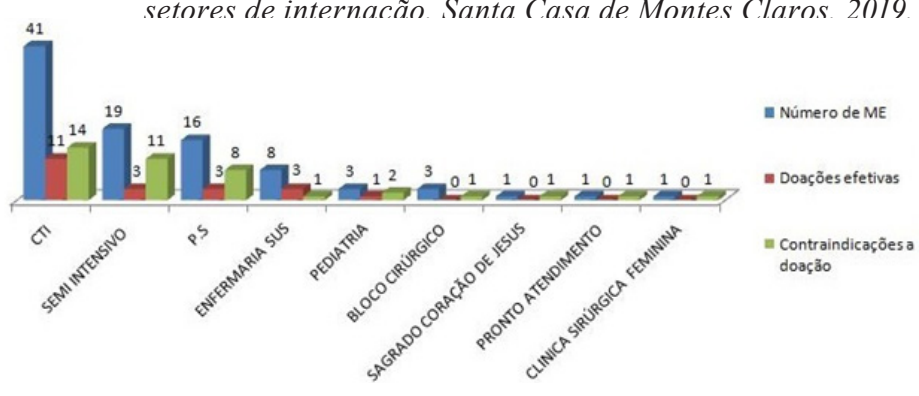

Fonte: Santa Casa de Montes Claros, 2019

\section{DISCUSSÃO}

Os resultados obtidos com este estudo representaram as principais características dos doadores elegíveis do hospital da Santa Casa da Misericórdia de Montes Claros - Minas Gerais, entre janeiro de 2018 a janeiro de 2019. Essa instituição possui funcionamento efetivo da CIHDOTT, desde 2009, sendo formada por um(a) médico(a), um(a) enfermeiro(a) e um(a) psicólogo(a), que desempenham a tarefa de busca ativa de potenciais doadores e abordagem familiar.

$\mathrm{Na}$ amostra estudada, evidenciou-se que 53 dos potenciais doadores eram do sexo masculino; desses, $20,7 \%$ (11 casos) tornaram-se doadores efetivos. O sexo feminino representou 32 dos potenciais doadores; desses, $21,8 \%$ (sete casos) tornaram-se doadores. Em valores absolutos, notou-se predomínio de doações do sexo masculino (61\%); no entanto, em valores relativos, o sexo feminino prevaleceu. Alguns estudos corroboram a predominância do sexo masculino como potencial doador de órgãos, o que pode relacionar-se com maior prevalência de morte prematura nesse sexo, ou ainda, pela maior aceitação familiar à doação..$^{10,11}$

A faixa etária predominante encontrada, entre 40 e 60 anos de idade (44\%), assemelha-se à verificada em outros estudos.10,12,13 No serviço estudado, foi obtido um número satisfatório de doações em pacientes jovens, entre zero e 25 anos (33\%), o que difere de alguns estudos que evidenciam maior dificuldade de aceitação familiar em pacientes mais jovens. ${ }^{10,12}$

Dentre as causas de óbito, predominaram AVE hemorrágico (35\%), AVE isquêmico (16\%) e TCE (30\%). Essas causas citadas são as prevalentes em todos os estudos pesquisados. Considerando-se os 85 casos de morte encefálica que foram notificados, os doadores viáveis representaram apenas $52 \%$ da amostra, sendo que $48 \%$ possuíam contraindicação à doação, estando esse valor muito acima de outros resultados da literatura..$^{10,12,13}$ Isso pode justificar-se pela dificuldade ainda existente na instituição para diagnosticar um potencial doador e iniciar o protocolo de ME prontamente. Sepse representou $41 \%$ das contraindicações, seguida pela idade avançada e pela Doença de Chagas, patologia frequente na região estudada, norte de Minas Gerais.

Entre os doadores viáveis, evidenciaram-se $58 \%$ de aceitação e $42 \%$ de recusa familiar. Esse resultado supera a expectativa de dados apresentados pela Associação Brasileira de Transplante de Órgãos (ABTO) em 2014. Não foi possível analisar a identificação do motivo da recusa. Porém, a maioria dos familiares parecia não compreender exatamente o significado de morte encefálica, o que corrobora com estudos que apontam a falta de conhecimento acerca do diagnóstico de morte encefálica como um dos principais motivos de recusa. ${ }^{14}$ 
$\mathrm{Na}$ tentativa de relacionar os setores de internação do paciente à aceitação familiar, notou-se que os potenciais doadores admitidos em UTI apresentaram $40 \%$ de aceitação familiar para doação. No setor de cuidados semi-intensivos e no Pronto-Socorro (PS), a aceitação familiar abarcou $37,5 \%$ dos casos. Esse dado de aceitação familiar dos pacientes admitidos no PS com pacientes admitidos em UTI ou em unidade semiintensivos foi surpreendente, visto que o vínculo familiar é mais difícil de ser constituído em uma porta de entrada do que no setor de internação.

Considerando-se os órgãos captados, foram obtidos 25 rins, seguidos de oito fígados e três corações. Doações de córneas em pacientes de coração parado foram excluídas do presente estudo. A captação e o transplante de fígado e rins ocorrem no próprio hospital. Já a captação e o transplante do coração foram feitos por uma equipe de Belo Horizonte, o que dificultou o processo de doação desse órgão. No entanto, desde a primeira captação de coração que ocorreu na instituição em outubro de 2018, houve boa comunicação e integração entre as equipes, permitindo mais duas captações, até janeiro de 2019.

\section{CONCLUSÃO}

Este estudo permitiu concluir que no hospital Santa Casa de Montes Claros houve predominância de doadores do gênero masculino, na faixa etária entre 40 e 60 anos, tendo como causa principal de morte AVE, com $52,5 \%$, seguido de TCE, com $31 \%$. Observou-se que $48 \%$ de casos apresentaram contraindicação para a doação, entre os quais predominou a sepse com $41 \%$. Dos familiares entrevistados; $42 \%$ recusaram-se a doar, não sendo possível estabelecer relação com o setor de internação no hospital e dificuldade de assistência médica às famílias. Os rins foram os órgãos mais disponibilizados para transplante. Através dessa análise de dados foi possível compreender as dificuldades enfrentadas pelos profissionais de saúde envolvidos em todo o processo diagnóstico de morte encefálica e da manutenção do potencial doador, tornando-se necessários programas contínuos de capacitação interna e melhoria da estrutura hospitalar, a fim de solucionar os entraves que impedem o avanço dos indicadores da doação de órgãos na Santa Casa de Montes Claros.

\section{ABSTRACT}

Introduction: Brain death (BD) is defined as the total and irreversible cessation of all activities of the brain stem and brain hemispheres. In Brazil, the diagnosis of this condition is achieved by using two physical examinations and a complementary test. The confirmation of brain death and the multiple organ donation process are complex, and it is important that new studies be made on that issue, mainly in the Brazilian reality. Purpose: To analyze data of brain death and also related to organs donations in hospital Santa Casa de Montes Claros, Minas Gerais state. Methods: It was attained a quantitative, descriptive, retrospective research based on the data collection in hospital Santa Casa de Montes Claros, Minas Gerais state. By using the review of patient registries, we analyzed each patient suspected of brain death from January 2018 to January 2019, Data was organized in a Excel sheet with following variables: gender, age, cause of death, type of complementary exam used in the brain death protocol, time of conclusion of brain death protocol, contraindications for organ donation, cause of refusal from the family to organ donation, and the type and number of organs donated to transplants. Results: There was 92 brain-dead suspected cases, from these only 42 protocols of brain death was concluded with 18 multiple organ donations, and 13 family refusal. Conclusion: In the present study, it was possible to conclude that the major cause for brain death was hemorrhagic stroke; in addition, $48 \%$ brain-dead cases suspected were contraindicated to donation, with $42 \%$ family refusal from potential organ donors.

Keywords: Tissue and Organ Procurement; Transplantation; Brain Death. 
Análise de dados dos protocolos de morte encefálica e de doação de órgãos realizados no Norte de Minas Gerais no período de janeiro de 2018 a janeiro de 2019

\section{REFERÊNCIAS}

1. Morais TR, Morais MR. Doação de órgãos: é preciso educar para avançar. Saúde em Debate. 2012;36:633-9.

2. Moraes ELd, Massarollo MCKB. Recusa de doação de órgãos e tecidos para transplante relatados por familiares de potenciais doadores. Acta Paulista de Enfermagem. 2009;22:131-5.

3. Souza DRSd, Tostes PP, Silva AS. Morte Encefálica: Conhecimento e Opinião dos Médicos da Unidade de Terapia Intensiva. Revista Brasileira de Educação Médica. 2019;43(3):115-22.

4. Dalbem GG, Caregnato RCA. Doação de órgãos e tecidos para transplante: recusa das famílias. Texto \& Contexto Enfermagem. 2010;19:728-35.

5. Bertasi RAdO, Bertasi TGdO, Reigada $\mathrm{CPH}$, Ricetto E, Bonfim $\mathrm{KdO}$, Santos LA, et al. Perfil dos potenciais doadores de órgãos e fatores relacionados à doação e a não doação de órgãos de uma Organização de Procura de Órgãos. Revista do Colégio Brasileiro de Cirurgiões. 2019;46(3).

6. Brasil, Ministério da Saúde. Portaria n 1.752, de 23 de setembro de 2005. Determina a constituição de Comissão Intra-Hospitalar de Doação de Órgãos e Tecidos. Diário Oficial da União. 2005.

7. Gil AC. Como Elaborar Projetos de Pesquisa. 4a edição ed. São Paulo: EDITORA ATLAS S.A; 2002. 176 p.
8. Ribeiro MLDB, Silva HBE. Resolução CFM N².173/2017 Publicado no DOU de 15 de dezembro de 2017, Seção I, p. 274-6 Atenção para apostilamento no texto do ANEXO I.

9. Brasil, Conselho Nacional de Saúde. Resolução nº 466 de 12 de dezembro de 2012. Diretrizes e Normas Regulamentadoras de Pesquisas Envolvendo Seres Humanos. Diário Oficial da União. 2012.

10. Moraes ELd, Silva LBdBe, Moraes TCd, Paixão NCdSd, Izumi NMS, Guarino AdJ. The profile of potential organ and tissue donors. Revista Latino-Americana de Enfermagem. 2009;17:716-20.

11. Schwarz E, Gomes R, Couto MT, Moura ECd, Carvalho SdA, Silva SFCd. Política de saúde do homem. Revista de Saúde Pública. 2012;46:108-16.

12. Associação Brasileira de Transplante de Órgãos. Registro Brasileiro de Transplantes. Dimensionamento dos Transplantes no Brasil e em cada estado. Ano XX, N4. 2014.

13. Freire ILS, Vasconcelos QLDdAQd, Torres GdV, Araújo ECd, Costa IKF, Melo GdSM. Estrutura, processo e resultado da doação de órgãos e tecidos para transplante. Revista Brasileira de Enfermagem. 2015;68:837-45.

14. Teixeira RKC, Gonçalves TB, Silva JACd. A intenção de doar órgãos é influenciada pelo conhecimento populacional sobre morte encefálica? Revista Brasileira de Terapia Intensiva. 2012;24:258-62. 